DOI: $10.5455 / 2320-1770.1 j r \operatorname{cog} 20150435$

Research Article

\title{
Association of neonatal respiratory morbidity with timing of elective cesarean delivery
}

\author{
Shraddha K. Shetty ${ }^{*}$, Anil K. Shetty ${ }^{2}$
}

\begin{abstract}
${ }^{1}$ Department of Obstetrics \& Gynaecology, Kasturba Medical College, Manipal University, Mangalore, Karnataka, India

${ }^{2}$ Department of Paediatrics, Father Muller Medical College, Mangalore, Karnataka, India
\end{abstract}

Received: 14 February 2015

Accepted: 28 February 2015

\section{*Correspondence:}

Dr. Shraddha K. Shetty,

E-mail: shraddha_k1@rediffmail.com

Copyright: () the author(s), publisher and licensee Medip Academy. This is an open-access article distributed under the terms of the Creative Commons Attribution Non-Commercial License, which permits unrestricted non-commercial use, distribution, and reproduction in any medium, provided the original work is properly cited.

\begin{abstract}
Background: Elective Cesarean Delivery (ECD) rate has increased in both developed and developing countries due to obstetric indications and cesarean section on request. Neonatal respiratory morbidity is one of the complications of elective cesarean delivery performed before 39 weeks gestation. The aim of this study was to compare the risk of neonatal respiratory morbidity of elective caesarean section performed at $37^{+0}$ to $38^{+6}$ weeks with those delivered at 39 ${ }^{+0}$ to $41^{+6}$ weeks gestation.

Methods: A retrospective study was conducted on all pregnant women who were delivered by elective caesarean at a gestational age of $37^{+0}$ to $38^{+6}$ weeks and were compared with those delivered at $39^{+0}$ to $41^{+6}$ weeks. Maternal and neonatal characteristics, neonatal respiratory morbidity including: respiratory distress syndrome, transient tachypnea of the newborn, persistent pulmonary hypertension of newborn and serious respiratory morbidity were analyzed.

Results: Incidence of neonatal respiratory morbidity was $15.8 \%$ and $6.3 \%$ in neonates delivered at $37^{+0}$ to $38^{+6}$ weeks and $\geq 39$ weeks gestation respectively. Combined respiratory morbidity risk (Odds ratio: OR 2.82; 95\% Confidence interval CI: 1.34-5.94; P value $<0.05$ ) was significantly higher in the neonates delivered at $37^{+0}$ to $38^{+6}$ weeks compared with those delivered $\geq 39$ weeks. Risk of TTN (OR 2.6; 95\% CI: 0.95-7.45; P value 0.08) and RDS (OR 2.42; 95\% CI: 0.48-12.15; P value 0.45) increased by two fold in neonates delivered before 39 weeks.

Conclusions: Neonates delivered by elective cesarean at $37^{+0}$ to $38^{+6}$ weeks gestations are at increased risk of developing respiratory morbidity compared with infants delivered beyond 39 weeks. Respiratory morbidity can be reduced by delaying the ECD until 39 weeks of gestation.
\end{abstract}

Keywords: Elective cesarean delivery, Neonatal respiratory morbidity, Transient tachypnea of newborn, Gestational age

\section{INTRODUCTION}

Elective cesarean section at term, in an obstetric population without prenatally identified risk factors, remains associated with increased resuscitation risk with related implications for the neonate compared with vaginal delivery. ${ }^{1}$
M. Hourani and co-workers studied a total of 134 neonates delivered by elective cesarean at or beyond 37 weeks, found a significant risk for the development of respiratory complications $(\mathrm{P}=0.0001)$ in the neonates delivered before 39 weeks. ${ }^{2}$

Hansen and colleagues reported that the infants delivered by elective cesarean at 37 weeks had a $10 \%$ incidence of 
respiratory morbidity (defined as transient tachypnea of newborn, respiratory distress syndrome or persistent pulmonary hypertension of newborn) compared with $2.8 \%$ among infants delivered vaginally (OR 3.7; 95\% CI, 2.2-6.1).The relative risk increased with decreasing gestational age. $^{3}$

Proposed mechanisms for the association between ECD and respiratory morbidity include iatrogenic prematurity with surfactant deficiency ${ }^{4,5}$ and attenuation of the fetal catecholamine surge during labor. ${ }^{6,7}$

A significant reduction in neonatal RDS would be obtained if elective caesarean delivery were performed after $39^{+0}$ gestational weeks of pregnancy. ${ }^{8}$

\section{METHODS}

- Hospital based retrospective study

- Conducted at Government Lady Goshen hospital between October 2013 and March 2014.

\section{Inclusion criteria}

- Pregnant women with gestation between $37^{+0}$ and $41^{+6}$ weeks who underwent elective cesarean section

- $\quad$ Singleton pregnancies

- No maternal and fetal complications

\section{Exclusion criteria}

Pregnancies complicated by:

- Intrauterine fetal deaths,

- Emergency caesarean sections,

- Multiple pregnancies and

- Associated maternal and/or fetal complications

Case sheets were reviewed to obtain data regarding the demographic details like maternal age and parity. Neonatal outcome analyzed included birth weight, sex of the baby, APGAR score at 1 and 5 minutes, NICU admission (admission more than 3 days), neonatal respiratory morbidity like transient tachypnea of newborn, respiratory distress syndrome and persistent pulmonary hypertension and serious respiratory morbidity (oxygen therapy for more than two days, nasal continuous positive airway pressure, or need for mechanical ventilation).

\section{Objectives}

- To determine the incidence of neonatal respiratory morbidity in elective caesarean section performed at $37^{+0}$ to $38^{+6}$ weeks of gestation and those delivered $\geq 39$ weeks.
- To compare the risk of neonatal respiratory morbidity after elective cesarean delivery at $37^{+0}$ to $38^{+6}$ weeks of gestation with those delivered $\geq 39$ weeks of gestation.

\section{Statistical analysis}

Patients' data were analyzed using SPSS 17.0.Chi-square test and unpaired t-student test used wherever appropriate. $\mathrm{P}$ value, odds ratio and $95 \%$ Confidence Interval were calculated. A value of $\mathrm{P}<0.05$ was considered significant.

\section{RESULTS}

During the study period of six months, there were 2890 deliveries. Of these, $1739(60.2 \%)$ neonates were delivered vaginally and $1151(39.8 \%)$ by cesarean section. Of 1151 cesarean sections, 202 (17.5\%) elective cesarean delivery (ECD) performed between $37^{+0}$ and $38^{+6}$ weeks and160 (13.9\%) between $39^{+0}$ and $41^{+6}$ weeks (Figure 1). Maternal and neonatal characteristics are shown in (Table 1). Mean maternal age \pm SD (years) was $27.3 \pm 4.9$ and $26.2 \pm 4.6$ years respectively in both the groups found to be statistically significant $(\mathrm{P}$ value $<0.05)$. There were no significant differences in both groups in relation to parity of the mothers and birth weight of neonates $(\mathrm{P}=0.76$; 0.6 respectively). We found that $20(9.95 \%)$ neonates delivered before 39 weeks and 6 $(3.75 \%)$ neonates born after 39 weeks gestation by ECD were admitted in NICU for more than 3 days (statistically significant differences found between two groups i.e. $\mathrm{P}$ value $<0.05)$.

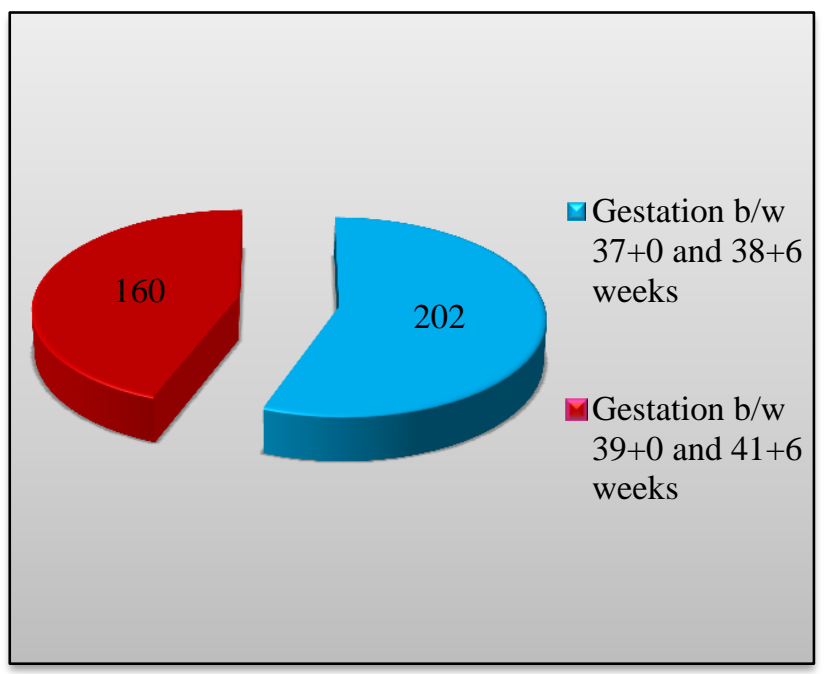

Figure 1: Number of elective cesarean delivery.

Indications of elective caesarean section shown in (Figure 2) shows that previous LSCS was the commonest indication for elective caesarean delivery in both the groups i.e., $150(74.3 \%)$ between $37^{+0}$ and $38^{+6}$ weeks and $128(80 \%)$ between $39^{+0}$ and $41^{+6}$ weeks. 
Table 1: Maternal and neonatal characteristics.

\begin{tabular}{|c|c|c|c|}
\hline \multirow{2}{*}{$\begin{array}{l}\text { Maternal \& } \\
\text { neonatal } \\
\text { characteristics }\end{array}$} & \multicolumn{2}{|c|}{ Gestational age (week) } & \multirow[b]{2}{*}{$\begin{array}{l}P \\
\text { value }\end{array}$} \\
\hline & $\begin{array}{l}37^{+0} \text { to } 38^{+6} \\
N(\%)\end{array}$ & $\begin{array}{l}39^{+0} \text { to } 41^{+6} \\
N(\%)\end{array}$ & \\
\hline \multicolumn{4}{|c|}{ Maternal characteristics } \\
\hline \multicolumn{4}{|l|}{ Maternal age (years) } \\
\hline$<35$ & $179(88.6)$ & $146(91.3)$ & 0.52 \\
\hline$\geq 35$ & $23(11.4)$ & $14(8.7)$ & \\
\hline $\begin{array}{l}\text { Mean age } \pm \text { SD } \\
\text { (years) }\end{array}$ & $27.3 \pm 4.9$ & $26.2 \pm 4.6$ & $0.03 *$ \\
\hline \multicolumn{4}{|l|}{ Parity } \\
\hline 0 & $39(19.3)$ & $28(17.5)$ & 0.76 \\
\hline$\geq 1$ & $163(80.6)$ & $132(82.5)$ & \\
\hline \multicolumn{4}{|c|}{ Neonatal characteristics } \\
\hline Male & $90(44.5)$ & $95(59.4)$ & $0.007 *$ \\
\hline Female & $112(55.4)$ & $65(40.6)$ & \\
\hline \multicolumn{4}{|c|}{ Birth weight (kilograms) } \\
\hline Mean birth wt. (kg) & $3.02 \pm 0.55$ & $2.99 \pm 0.54$ & \\
\hline$<2.5$ & $29(14.4)$ & $17(10.6)$ & 0.60 \\
\hline $2.5-4$ & $160(79.2)$ & $128(80)$ & \\
\hline$>4$ & $13(6.4)$ & $15(9.4)$ & \\
\hline${ }^{* *}$ NICU admission & $20(9.9)$ & $6(3.75)$ & $0.041 *$ \\
\hline
\end{tabular}

The number of infants who developed respiratory morbidity after elective cesarean between $37^{+0}$ and $41^{+6}$ weeks are shown in (Table 2). The incidence of combined respiratory morbidity was $15.8 \%$ and $6.3 \%$ after elective caesarean delivery at $37^{+0}$ to $38^{+6}$ weeks and $39^{+0}$ to $41^{+6}$ weeks respectively (Figure 3 ).

The neonatal respiratory morbidity risk (OR 2.82;95\% CI:1.34-5.94; $\mathrm{P}$ value <0.05) was significantly higher in the neonatal group delivered by ECD at $37^{+0}$ weeks to $38^{+6}$ weeks compared with those delivered at $39^{+0}$ to $41^{+6}$ weeks. Risk of TTN (OR 2.6; 95\% CI: 0.95-7.45; P value 0.08 ) and RDS (OR 2.42; 95\%CI: 0.48-12.15; P value 0.45 ) increased by two fold at $37^{+0}$ and $38^{+6}$ weeks. Serious respiratory morbidity included oxygen therapy for more than two days, nasal continuous positive airway pressure, or need for mechanical ventilation. (OR 2.15; 95\% CI: $0.56-8.27$; P value-0.40) was found in $3.8 \%$ and $1.9 \%$ neonates delivered before and after 39 weeks respectively (Table 2).

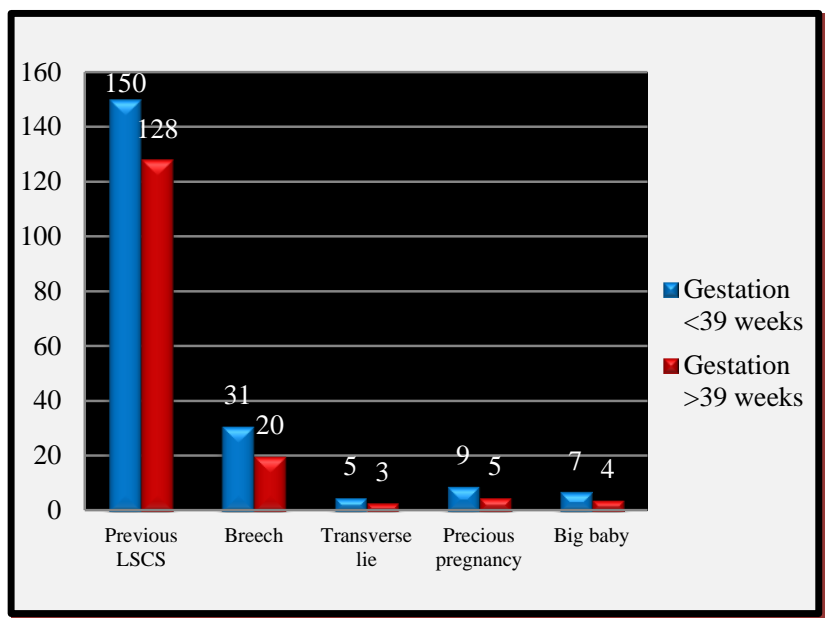

Figure 2: Indications of elective cesarean delivery.

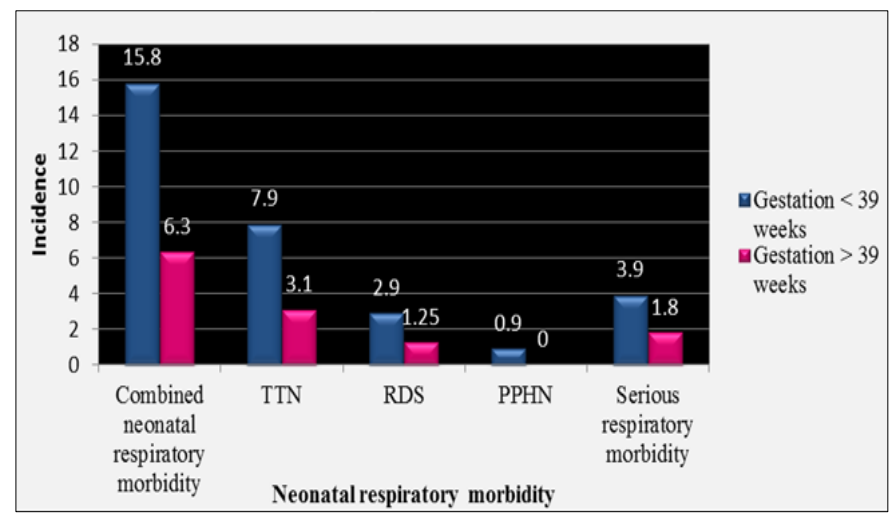

Figure 3: Incidence of neonatal respiratory morbidity following ECD beyond 37 weeks.

Table 2: Neonatal respiratory morbidity following elective cesarean delivery.

\begin{tabular}{|c|c|c|c|c|}
\hline Neonatal respiratory morbidity & $\begin{array}{l}\mathrm{ECD} b / \mathrm{w} 37^{+0} \& 38^{+6} \\
\text { weeks }(\mathrm{n}=202) \mathrm{N}(\%)\end{array}$ & $\begin{array}{l}\mathrm{ECD} \mathrm{b} / \mathrm{w} 39^{+0} \& 41^{+6} \\
\text { weeks }(\mathrm{n}=160) \mathrm{N}(\%)\end{array}$ & OR $(95 \% \mathrm{CI})$ & P value \\
\hline $\begin{array}{l}\text { Total no. of infants with combined } \\
\text { respiratory morbidity }\end{array}$ & $32(15.8)$ & $10(6.3)$ & $2.82(1.34-5.94)$ & $0.007 *$ \\
\hline Transient tachypnea of new-born & $16(7.9)$ & $5(3.1)$ & $2.6(0.95-7.45)$ & 0.08 \\
\hline Respiratory distress syndrome & $6(2.9)$ & $2(1.25)$ & $2.42(0.48-12.15)$ & 0.45 \\
\hline Persistent pulmonary hypertension & $2(0.9)$ & 0 & - & 0.58 \\
\hline Serious respiratory morbidity ${ }^{* *}$ & $8(3.9)$ & $3(1.8)$ & $2.15(0.56-8.27)$ & 0.40 \\
\hline
\end{tabular}

* Statistically significant $p$ value $(<0.05)$

**Oxygen therapy for more than 2 days; Nasal continuous positive airway pressure; Need for mechanical ventilation

OR: Odds ratio; CI: Confidence interval; ECD: Elective cesarean delivery 


\section{DISCUSSION}

In our study, we analyzed 202 neonates delivered by elective cesarean section before 39 weeks and 160 neonates delivered beyond 39 weeks of gestation. The incidence of neonatal respiratory morbidity was $15.8 \%$ in elective cesarean section performed between $37^{+0}$ and $38^{+6}$ weeks and $6.3 \%$ between $39^{+0}$ and $41^{+6}$ weeks while TTN and RDS was observed in $7.9 \%$ and $2.9 \%$ compared to $3.1 \%$ and $0.9 \%$ respectively. The incidence of respiratory morbidity after elective cesarean delivery was $25 \%$ at 38 weeks compared to $11 \%$ in elective cesarean delivery beyond 39 weeks while TTN was observed in $10 \%$ compared to $7 \%$ of newborns respectively in a study conducted by S. Hefny and colleagues. ${ }^{9}$ We found that neonatal respiratory morbidity risk (OR 2.82; 95\% CI: 1.34-5.94; $\mathrm{P}$ value <0.05) was significantly higher in elective cesarean section performed before 39 weeks of gestation, similar results were observed in Zanardo $\mathrm{V}$ et al. study. ${ }^{8}$

In the present study, TTN (OR 2.6; 95\% CI: 0.95-7.45; P value 0.08 ) and RDS (OR 2.42; 95\%CI: 0.48-12.15; P value 0.45 ) risk is increased by two fold in elective cesarean delivery performed before 39 weeks. Hansen and co-workers ${ }^{3}$ reported that there was a fivefold increased risk of respiratory morbidity in infants delivered by ECD at 37 weeks (OR 5.0; 95\%CI: 1.616.0).

Hamida Ben and colleagues observed that there was a significant reduction in the incidence of respiratory distress from elective caesarean performed after 39 weeks gestation. ${ }^{10}$ In the present study, $3.8 \%$ neonates delivered by Elective cesarean delivery before 39 weeks developed serious respiratory morbidity while in the Hansen study, $1.9 \%$ of infants delivered by ECD at 37 weeks experienced serious respiratory morbidity. ${ }^{3}$

\section{CONCLUSIONS}

Neonatal respiratory morbidity risk is significantly increased in neonates delivered by elective cesarean section before 39 weeks gestation. Our results suggest that reduction in the neonatal respiratory morbidity would be achieved by delaying the elective cesarean delivery until 39 weeks.
Funding: No funding sources Conflict of interest: None declared

Ethical approval: Not required

\section{REFERENCES}

1. Zanardo V, Simbi KA, Vedovato S, Trevisanuto D. The influence of timing of elective cesarean section on neonatal resuscitation risk. Pediatr Crit Care Med. 2004;5(6):566-70.

2. Hourani M, Ziade F, Rajab M. Timing of planned caesarean section and the morbidities of the newborn. N Am J Med Sci. 2011 Oct;3(10):465-8.

3. Hansen AK, Wisborg K, Uldbjerg N, Henriksen TB. Risk of respiratory morbidity in term infants delivered by elective caesarean section: cohort study. BMJ. 2008;336:85-7.

4. Parilla BV, Dooley SL, Jansen RD, Socol ML. Iatrogenic respiratory distress syndrome following elective repeat cesarean delivery. Obstet Gynecol. 1993;81:392-5.

5. Wax JR, Herson V, Carignan E, Mather J, Ingardia CJ. Contribution of elective delivery to severe respiratory distress at term. Am J Perinatol. 2002;19:81-6.

6. Falconer AD, Lake DM. Circumstances influencing umbilical-cord plasma catecholamines at delivery. $\mathrm{Br}$ J Obstet Gynaecol. 1982;89:44-9.

7. Faxelius G, Hägnevik K, Lagercrantz H, Lundell B, Irestedt L. Catecholamine surge and lung function after delivery. Arch Dis Child. 1983;58:262-6.

8. Zanardo V, Simbi AK, Franzoi M, Solda' G, Salvadori A, Trevisanuto D. Neonatal respiratory morbidity risk and mode of delivery at term: Influence of timing of elective caesarean delivery. Acta Pædiatr. 2004;93:643-7.

9. Hefny SM, Taher Hashem AM, Abdel-Razek AR, Ayad SM. The neonatal respiratory outcome in relation to timing of elective cesarean section at 38 versus 39 week gestation: a single center based study. J EPAG. 2013;61:78-82.

10. Ben Hamida Nouaili E, Bouziri A, Ben Miled A, Chaouachi S, Sfar R, Ben Jaballah N. Neonatal respiratory morbidity after elective cesarean section at term. Tunis Med. 2010 Dec;88(12):924-7.

DOI: $10.5455 / 2320-1770 . i j r \operatorname{cog} 20150435$

Cite this article as: Shetty SK, Shetty AK.

Association of neonatal respiratory morbidity with timing of elective cesarean delivery. Int J Reprod Contracept Obstet Gynecol 2015;4:461-4. 